INTRODUCTION TO ENGINEERING MATERIALS 
Other Materials-related titles from Macmillan Education

Work Out Engineering Materials V B John

Non-destructive Testing J B Hull \& V B John

Testing of Materials V B John

Civil Engineering Materials 4th edition N Jackson \& R Dhir

Reinforced Concrete Design 4th edition W H Mosley \& J H Bungey

Polymer Materials 2nd edition C Hall

Strength of Materials 3rd edition G H Ryder

Structural Mechanics J Cain \& R Hulse

Work Out Structural Mechanics R Hulse \& J Cain

Macmillan Dictionary of Materials and Manufacturing V B John (editor) 


\section{Introduction to Engineering Materials}

Vernon John

Bsc, MSc, CEng, MIM, MIMM

Formerly Senior Lecturer in Materials

The Polytechnic of Central London

Third Edition

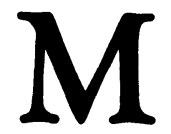

MACMILLAN 
(C) V. B. John 1972, 1983, 1992

All rights reserved. No reproduction, copy or transmission of this publication may be made without written permission.

No paragraph of this publication may be reproduced, copied or transmitted save with written permission or in accordance with the provisions of the Copyright, Designs and Patents Act 1988, or under the terms of any licence permitting limited copying issued by the Copyright Licensing Agency, 90 Tottenham Court Road, London W1P 9HE.

Any person who does any unauthorised act in relation to this publication may be liable to criminal prosecution and civil claims for damages.

First published 1972 by

THE MACMILLAN PRESS LTD

Houndmills, Basingstoke, Hampshire RG21 2XS

and London

Companies and representatives

throughout the world

ISBN 978-0-333-57715-8 ISBN 978-1-349-21976-6 (eBook)

DOI 10.1007/978-1-349-21976-6

ISBN 978-0-333-56827-9 paperback

A catalogue record for this book is available

from the British Library.

Reprinted 1973, 1974, 1977, 1978, 1979, 1981, 1982

Second edition 1983

Reprinted 1986, 1988, 1990

Third edition 1992

Reprinted 1993 


\section{Contents}

Prefaces

$x i$

Symbols used in text xiv

Units

$x v$

\section{PART I \\ INTRODUCTION}

1 The Materials of Engineering

1.1 Introduction; 1.2 The range of materials; 1.3 Properties of engineering materials; 1.4 Cost and availability; 1.5 Possibilities for the future.

\section{PART II \\ MATERIALS SCIENCE}

2 Atomic Structure and Bonding

2.1 Introduction; 2.2 Elementary particles; 2.3 Atomic number and atomic mass number; 2.4 Isotopes and isotones; 2.5 The gramme atom, gramme molecule and Avogadro's number; 2.6 The structure of the atom and quantum numbers; 2.7 The Pauli exclusion principle; 2.8 The periodic table; 2.9 The nucleus and radioactivity; 2.10 Artificial radioactive materials; 2.11 Interatomic and intermolecular bonding; 2.12 The ionic bond; 2.13 The covalent bond; 2.14 The co-ordinate bond; 2.15 The metallic bond; 2.16 Secondary bonds; 2.17 Mixed bonds; 2.18 Questions.

3 Influence of Bond Type on Structure and Properties

3.1 Introduction; 3.2 Structure and density; 3.3 Stability and melting point; 3.4 Stiffness; 3.5 Electrical properties.

4 The Formation of Polymers

4.1 Introduction; 4.2 Addition polymerisation; 4.3 Condensation polymerisation; 4.4 Linear and non-linear polymers; 4.5 Branching; 4.6 Cross-linking; 4.7 Stereoregularity; 4.8 Degree of polymerisation; 4.9 Polymerisation methods; 4.10 Questions. 
5.1 Introduction; 5.2 Crystal classes; 5.3 Miller notation; 5.4 Metallic crystals; 5.5 Interstitial sites; 5.6 Ceramic crystals; 5.7 Silica and silicates; 5.8 Analysis of crystals; 5.9 Questions.

6 Glasses and Partial Crystallinity

6.1 Introduction; 6.2 Formation of glasses; 6.3 Inorganic glasses; 6.4 Metallic glasses; 6.5 Polymer glasses; 6.6 Crystallinity in polymers.

7 Elastic Behaviour

7.1 Stress and strain; 7.2 Elastic constants; 7.3 Fibre reinforced composites; 7.4 Thermal stresses; 7.5 Toughened glass; 7.6 Questions.

8 Dislocations and Plasticity in Metals

8.1 Plastic flow in metals; 8.2 Slip planes; 8.3 Dislocations; 8.4 Deformation by twinning; 8.5 Polycrystalline metals; 8.6 Plastic deformation and strain hardening; 8.7 Recrystallisation; 8.8 Solution hardening; 8.9 Dispersion hardening; 8.10 Yield point in mild steel; 8.11 Diffusion and dislocation climb; 8.12 Superplasticity; 8.13 Questions.

9 Viscoelastic Behaviour

9.1 Introduction; 9.2 Viscoelasticity; 9.3 The Maxwell model; 9.4 Voigt-Kelvin model; 9.5 Other models; 9.6 Questions.

10 Toughness and Fracture of Materials

10.1 Introduction; 10.2 Crack propagation in materials; 10.3 Fracture mechanics; 10.4 Applications of $\mathrm{K}_{\mathrm{Ic}} ; 10.5$ Effect of temperature; 10.6 Determination of fracture toughness; 10.7 Yielding fracture mechanics; 10.8 Conclusion; 10.9 Questions.

11 Phase Diagrams and Alloy Formation

11.1 Introduction; 11.2 Alloy systems; 11.3 Total solid insolubility; 11.4 Interpretation of phase diagrams; 11.5 Solid solubility; 11.6 Phase diagram for total solid solubility; 11.7 Partial solid solubility; 11.8 Peritectic diagram; 11.9 Compound formation; 11.10 Effect of alloy type on properties in metallic systems; 11.11 Allotropy; 11.12 Ternary diagrams; 11.13 Questions. 
12.1 Introduction; 12.2 Thermally activated processes; 12.3 Diffusion; 12.4 Fick's laws of diffusion; 12.5 Carburising and decarburising; 12.6 Precipitation hardening; 12.7 Martensitic transformations; 12.8 Phase transformations in ceramics and glasses; 12.9 Questions.

13 Electrical and Magnetic Properties

13.1 Conduction; 13.2 Band structure; 13.3 Conduction in metals; 13.4 Semiconductors; 13.5 The $\mathrm{p}-\mathrm{n}$ junction; 13.6 Insulating materials; 13.7 Ferroelectric materials; 13.8 Piezo-electric effect; 13.9 Magnetic behaviour; 13.10 The Hall effect.

14 Optical, Thermal and Other Properties

14.1 Electron excitation; 14.2 The energy spectrum; 14.3 Absorption and transmission; 14.4 Refraction and polarisation; 14.5 Diffraction; 14.6 Luminescence; 14.7 Heat capacity; 14.8 Thermal expansion; 14.9 Thermal conductivity; 14.10 Sound absorption and damping; 14.11 Interface effects and surface tension; 14.12 Friction and lubrication; 14.13 Questions.

\section{PART III \\ THE MATERIALS OF ENGINEERING}

15 Non-ferrous Metals and Alloys

15.1 Introduction; 15.2 Aluminium; 15.3 Aluminium alloys; 15.4 Copper; 15.5 Copper alloys; 15.6 Lead; 15.7 Tin; 15.8 Magnesium; 15.9 Nickel; 15.10 Titanium; 15.11 Zinc; 15.12 Bearing materials; 15.13 Superalloys.

16 Iron and Steel

16.1 Introduction; 16.2 Production of iron; 16.3 Steel production; 16.4 Constituents in steels; 16.5 The iron-carbon phase diagram; 16.6 Structures of plain carbon steels; 16.7 T-T-T diagrams; 16.8 Hardenability; 16.9 Tempering; 16.10 Heat treatments for steels; 16.11 Types of steels and their uses; 16.12 Surface hardening; 16.13 The effects of alloying elements in steels; 16.14 Alloy steels; 16.15 Cast irons; 16.16 Malleable irons; 16.17 Alloy cast irons; 16.18 Questions.

17.1 Introduction; 17.2 Polyethylene (PE); 17.3 Ethylene copolymers; 17.4 Polypropylene (PP); 17.5 Polyvinyl chloride (PVC); 17.6 Polytetrafluoroethylene (PTFE); 17.7 Polystyrene (PS); 17.8 Acrylic materials; 17.9 Polyamides (nylons) (PA); 17.10 Polycarbonate (PC); 17.11 Acetal (POM); 17.12 Saturated polyesters; 17.13 Cellulosics; 17.14 PEEK; 17.15 Polyphenylenes; 17.16 Polysulphones and polyarylates; 17.17 Polyimides. 
18.1 Introduction; 18.2 Natural rubber (NR); 18.3 Synthetic R class elastomers; $18.4 \mathrm{M}$ class elastomers; 18.5 O class elastomers; 18.6 U class elastomers; 18.7 Q class elastomers; 18.8 Thermoplastic elastomers.

19 Thermosetting Materials

19.1 Introduction; 19.2 Phenolic materials; 19.3 Amino-formaldehyde materials; 19.4 Polyester materials; 19.5 Epoxide materials; 19.6 Polyurethanes; 19.7 Allyl resins.

20 Ceramics and Glasses

20.1 Introduction; 20.2 Building stone; 20.3 Cement and concrete; 20.4 Clay and clay products; 20.5 Refractories; 20.6 Industrial ceramics; 20.7 Alumina; 20.8 Silicon nitride; 20.9 Sialons; 20.10 Silicon carbide; 20:11 Boron nitride and other ceramics; 20.12 Glass ceramics; 20.13 Glasses.

21 Composite Materials

21.1 Introduction; 21.2 Timber and plywood; 21.3 Fibre reinforced materials; 21.4 Fibres; 21.5 Matrix materials; 21.6 Metal matrix composites (MMC); 21.7 Cermets; 21.8 Sandwich structures.

\section{PART IV \\ FORMING AND FABRICATION OF MATERIALS}

\section{Forming Processes for Metals}

22.1 Introduction; 22.2 Melting furnaces; 22.3 Melting and alloying; 22.4 Melt treatment; 22.5 Casting; 22.6 Sand casting; 22.7 Die casting; 22.8 Investment casting; 22.9 Centrifugal casting; 22.10 Ingot casting; 22.11 Hot working; 22.12 Fibre Structure; 22.13 Cold working; 22.14 Annealing; 22.15 Powder metallurgy.

23.1 Introduction; 23.2 Forming of thermoplastics; 23.3 Injection moulding; 23.4 Extrusion; 23.5 Calendering; 23.6 Thermoplastic sheet forming; 23.7 Rotational moulding; 23.8 Expanded plastics; 23.9 Forming of thermosets; 23.10 Reaction injection moulding (RIM); 23.11 Moulding of fibre composites; 23.12 Preforms, prepregs and moulding compounds; 23.13 Laminating. 
24.1 Forming of clay ceramics; 24.2 Pressing; 24.3 Sintering; 24.4 Reaction bonding and reaction sintering; 24.5 Injection moulding; 24.6 Manufacture of glass; 24.7 Forming processes for glass.

\section{Material Removal Processes}

25.1 Introduction; 25.2 The cutting process; 25.3 Chip formation; 25.4 Cutting tool life; 25.5 Cutting fluids; 25.6 Cutting tool materials; 25.7 Machinability; 25.8 Forming and generating; 25.9 Single point machining; 25.10 Multipoint machining; 25.11 Abrasive machining and finishing; 25.12 Gear and thread manufacture; 25.13 Non-traditional machining processes.

26 Joining Processes

26.1 Introduction; 26.2 Soldering and brazing of metals; 26.3 Fusion welding of metals; 26.4 Other fusion welding processes for metals; 26.5 Pressure welding of metals; 26.6 Diffusion joining; 26.7 The welding of plastics; 26.8 Adhesive bonding; 26.9 Metallurgical considerations for welding; 26.10 Defects in welds.

\section{PART V \\ BEHAVIOUR IN SERVICE}

27 Failure, Fatigue and Creep

409

27.1 Failure; 27.2 Fatigue; 27.3 Crack nucleation and growth; 27.4 Factors affecting fatigue; 27.5 Creep; 27.6 Relaxation; 27.7 Questions.

28 Oxidation, Corrosion and Other Effects

28.1 Oxidation of metals; 28.2 Degradation of polymers; 28.3 Oxidation of ceramics and composites; 28.4 Corrosion; 28.5 Corrosion protection; 28.6 Microbial attack; 28.7 Effects of radiation; 28.8 Questions.

\section{PART VI \\ EVALUATION OF MATERIALS}

29 Property Testing

29.1 Introduction; 29.2 Hardness tests; 29.3 Relationships between hardness and other properties; 29.4 Tensile, compressive and shear testing; 29.5 Testing machines; 29.6 Measurement of strain; 29.7 The tensile testing of metals; 29.8 True stress and true strain; 29.9 The 
tensile testing of plastics; 29.10 Determining the tensile strength of brittle materials; 29.11 Compression testing; 29.12 Testing in shear; 29.13 Notch impact testing; 29.14 Fatigue testing; 29.15 Creep testing; 29.16 Relaxation testing; 29.17 Questions.

30 Non-destructive Testing

30.1 Introduction; 30.2 Visual inspection; 30.3 Liquid penetrant inspection; 30.4 Magnetic particle inspection; 30.5 Electrical test methods; 30.6 Ultrasonic inspection; 30.7 Principles of radiography; 30.8 Acoustic emission inspection; 30.9 Vibration testing; 30.10 Questions.

31 Macro- and Micro-examination

31.1 Macro-examination; 31.2 Micro-examination of metals; 31.3 Micro-examination of non-metals; 31.4 Transmission electron microscopy; 31.5 Scanning electron microscopy; 31.6 Other analytical techniques.

\section{Materials Selection}

32.1 Introduction; 32.2 Parameters to be considered; 32.3 Costs; 32.4 The selection process. 


\section{Preface to the First Edition}

Not many years ago it was possible to obtain a first degree or other qualification in engineering with no knowledge whatsoever of metallurgy or the other materials of engineering. Today it is fully accepted that a sound knowledge of the science and technology of materials is very necessary to the engineer if he is to be able efficiently to translate a design into functional 'hardware'. The selection of materials and manufacturing route is an integral part of design procedure. Because of this, materials' science and technology now feature prominently in the educational programme for all engineering technologists and technicians. Engineering, including materials' science, is also beginning to appear in the curricula of some schools.

This book was conceived against the general background of the changing patterns in engineering education, and the aim was to produce a text which dealt with the basic principles of materials science and technology in a simple, yet meaningful manner.

It is my belief that no aspect of engineering should be studied in a vacuum, but that academic studies be related to our real cost-conscious world. It is for this reason that I have included some materials' costs and a short note on the selection of materials. Although actual costs will vary from year to year, this section should be of value as it indicates the principle that any work or processing performed on a material is reflected in an increase in the cost of the material.

I wish to acknowledge the help and advice received from various individuals and organisations, and in particular to thank Professor Bob Fergusson for providing the initial stimulus for this work. I am indebted to some of my colleagues at PCL, especially Mr C. J. Beesley, Mr G. E. Drabble, and $\mathrm{Mr}$ M. D. Munro Mackenzie, for their assistance in reading the manuscript and suggesting improvements. I also wish to acknowledge the assistance, in the way of photographs and information, which I received from the following firms and organisations: British Aluminium Company Ltd, British Metals Sinterings Association, Bound Brook Ltd, Copper Development Association, I.C.I. Ltd (Plastics Division), International Nickel Ltd, Raleigh Industries Ltd, Sintered Products Ltd, and the Zinc Development Association. Several colleges and polytechnics provided me with question papers, and I wish to record my appreciation of their help. Finally, I am very grateful to my wife for not merely putting up with me while I was struggling with the manuscript, but for helping considerably by sustaining me with refreshment and also typing some of the manuscript. 


\section{Preface to the Second Edition}

Ten years have elapsed since this book was first published and after such a period of time an updating is necessary for any technical text. In the preparation of this edition I have attempted to satisfy two objectives; firstly to keep a basic and straightforward approach so that the text can be readily understood by students beginning their studies, and secondly to broaden the scope of the volume and so increase its suitability for degree and diploma students of both mechanical and production engineering in the later years of their courses.

When preparing a new edition of a book an author is torn between the desire to tear everything up and start again with a ream of blank paper or merely to make small cosmetic changes. This book was generally well received when it was first published and students appeared to like the general style and content. I have, therefore, retained much of the original text and confined myself to meeting most of the criticisms (fortunately, these were not too numerous) levelled at the first edition and also to making changes that reflect the development in my own teaching at PCL.

Some of the major differences between this text and the first edition are: (1) the inclusion of more worked examples within the text, (2) an increase in the sections dealing with dislocations and plastic deformation within metals, (3) a substantial enlargement of the chapter on materialforming processes, (4) a major increase in the chapters devoted to plastics materials, (5) a more detailed treatment of oxidation and corrosion and (6) the development of a small section on welding, formerly placed as an Appendix, into a full chapter within the book. In addition to these changes, an introduction to the principles of fracture mechanics has been included as an Appendix to the main text. It is my hope that these changes will find favour with both students and teachers.

I wish to thank my colleagues in the Materials section at PCL for the helpful comments freely given during the preparation of this revision and to record my indebtedness to my wife for her great help and for the typing of the draft. 


\section{Preface to the Third Edition}

There is a process of continuous development for curricula for courses in engineering. One significant development of the last decade is that the subject of engineering materials has moved into a centre-stage position, especially as a subject field within mechanical and manufacturing engineering courses. There has also been debate on the subject of a 'core curriculum'. During the preparation of this revised and enlarged edition, I have attempted to cater for current curriculum developments and changes in emphasis within syllabi. One possible failing of the last edition was, perhaps, an overemphasis on metals. I have attempted to redress this with increased coverage of non-metallic materials. My aim has been to present that body of core knowledge in materials science and technology which, in my opinion, should be a necessary part of the educational programme for any engineer.

The earlier editions of this book were well received and feedback from students indicated that the style of writing and presentation was clear and understandable. In consequence, I have retained much of the original text and illustrations in this new edition, even though the general structure of the book has been changed significantly and the number of chapters increased. The principal changes from the second edition include an introductory chapter outlining the range of materials, their basic characteristics, costs and availability to set the scene. The materials science section has been enlarged with elasticity and plasticity separated into two chapters and with new chapters dealing with polymer formation, visco-elasticity, toughness and fracture, phase transformations, and optical and thermal properties. Worked examples have been included in the text where appropriate. There has been a major increase in the textual matter covering polymers, ceramics and glasses. The formation and fabrication of materials has been reorganised with separate chapters for each class of material and a new chapter for material removal processes. The importance of non-destructive testing has been recognised by including a new chapter devoted to this subject. Material which appeared as appendices in the last edition has now been incorporated into the main text. It is hoped that these changes will find general acceptance by both teachers and students.

I hope that those engineering students who read and use this book will be stimulated and encouraged in their studies. Also, that they will develop an understanding and a feel for materials so that, as practising engineers, they will be able to select and use materials effectively and efficiently.

Questions requiring numerical answers are included at the ends of chapters. For descriptive answer questions and further numerical problems, refer to Work Out Engineering Materials, also by Vernon John and published by Macmillan. 


\section{Symbols Used in Text}

Quantity

Atomic mass number (atomic weight)

Atomic number

Avogadro's number

Bulk modulus of elasticity

Density

Direct strain

Direct stress

Force

Fracture toughness

Glass transition temperature

Melting temperature

Modulus of rigidity

Poisson's ratio

Shear strain

Shear stress

Temperature

Time

Universal constant

Viscosity

Young's modulus of elasticity
Symbol

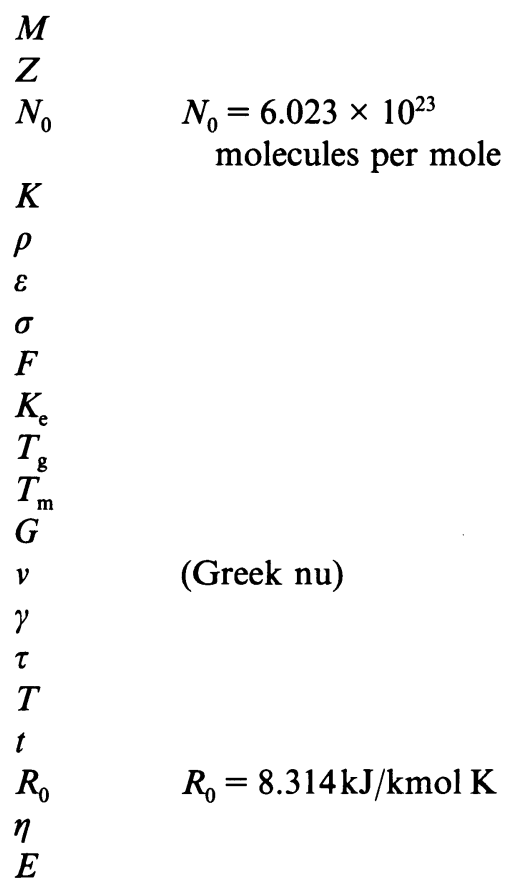

$Z$

$N_{0}$

$K$

$F$

Ke

$T_{\mathrm{m}}$

G

$\gamma$

$\tau$

$T$

$t$

E
$N_{0}=6.023 \times 10^{23}$

molecules per mole

(Greek nu)

$R_{0}=8.314 \mathrm{~kJ} / \mathrm{kmol} \mathrm{K}$ 


\section{Units}

The units used throughout this book conform to the SI system. The principal units that are quoted in the text are given below. Preferred SI units are printed in bold type.

Quantity

mass

length

time

temperature

amount of substance

area

volume

density

force

stress (pressure)

energy
Unit

kilogramme

gramme

tonne

metre

millimetre

second

minute

hour

degree Kelvin

degree Celsius

mole

kilomole

square metre

square millimetre

cubic metre

cubic millimetre

kilogramme per cubic metre

newton

kilonewton

meganewton

newton per square metre

meganewton per square

metre

giganewton per square metre

pascal

bar

joule

electron volt
Symbol

$\operatorname{kg}(1 \mathrm{~kg}=2.205 \mathrm{lb})$

$\mathrm{g}$

$\mathrm{t}(\mathrm{Mg})(1 \mathrm{t}=1000 \mathrm{~kg}$

$=0.984$ ton)

$\mathbf{m}(1 \mathrm{~m}=39.37 \mathrm{in})$

$\mathrm{mm}$

$\mathbf{s}$

$\min$

$\mathrm{h}$

K

${ }^{\circ} \mathrm{C}$

mol

kmol

$\mathbf{m}^{2}$

$\mathrm{mm}^{2}$

$\mathbf{m}^{3}\left(1 \mathrm{~m}^{3}=35.315 \mathrm{ft}^{3}\right)$

$\mathrm{mm}^{3}$

$\mathrm{kg} / \mathrm{m}^{3}\left(1 \mathrm{~kg} / \mathrm{m}^{3}\right.$

$$
=10^{-3} \mathrm{~g} / \mathrm{cm}^{3}
$$$$
\left.=0.062 \mathrm{lb} / \mathrm{ft}^{3}\right)
$$

$\mathrm{N}(1 \mathrm{~N}=0.225 \mathrm{lbf})$

$\mathrm{kN}$

MN

$\mathrm{N} / \mathbf{m}^{2}\left(1 \mathrm{~N} / \mathrm{m}^{2}\right.$ $\left.=0.000145 \mathrm{lbf} / \mathrm{in}^{2}\right)$

$\mathrm{MN} / \mathrm{m}^{2}\left(1 \mathrm{MN} / \mathrm{m}^{2}\right.$

$=0.0648$ tonf $/ \mathrm{in}^{2}$ )

$\mathrm{GN} / \mathrm{m}^{2}$

$\operatorname{Pa}\left(1 \mathrm{~Pa}=1 \mathrm{~N} / \mathrm{m}^{2}\right)$

bar or b $\left(1 \mathrm{bar}=10^{5} \mathrm{~N} / \mathrm{m}^{2}\right)$

$\mathbf{J}(\mathrm{Nm})$

$\mathrm{eV}(1 \mathrm{eV}$ $=1.602 \times 10^{-19} \mathrm{~J}$ ) 
electric current

voltage

quantity of electricity electrical resistance electrical resistivity

magnetic flux

magnetic flux density

frequency

\begin{abstract}
ampere
volt

coulomb

ohm

ohm metre

weber

tesla
\end{abstract}

hertz
$\mathbf{A}$

V

C (A s)

$\Omega(\mathrm{V} / \mathrm{A})$

$\Omega \mathbf{m}$

$\mathbf{W b}(\mathrm{V} \mathrm{s})$

$\mathrm{T}\left(\mathrm{Wb} / \mathrm{m}^{2}\right)$

( $1 \mathrm{~T}=10^{4}$ gauss)

Hz $\left(\mathrm{s}^{-1}\right)$ 